\title{
Clinical Testing in Diabetic Peripheral Neuropathy
}

\author{
Eva L. Feldman and Martin J. Stevens
}

\begin{abstract}
Diabetic polyneuropathy is a complex disease of progressive nerve fiber loss. Initial screening and diagnosis in clinical practice usually depend on assessment of subjective complaints. A need exists for objective, simple, and reproducible assessment tools that can be readily used in clinical practice. The importance of early diagnosis is highlighted by the recent North American Diabetes Control and Complications Trial where intensive insulin therapy reduced the risk of developing diabetic neuropathy by $61 \%$. At the University of Michigan, we have developed an outpatient neuropathy program. Patients are given a questionnaire and a brief screening examination, designated the Neuropathy Screening Instrument. Diabetic neuropathy is confirmed and staged in patients with a positive Neuropathy Screening Instrument, by a quantitative neurologic examination and nerve conduction studies, designated the Diabetic Neuropathy Score. The Michigan program has been compared with wellestablished instruments and has been found to be sensitive and reproducible for screening and diagnosis. We believe the program provides a valuable tool for the clinician in the practice setting and should allow diagnosis and intervention earlier in the course of diabetic neuropathy.
\end{abstract}

\begin{abstract}
Résumé: Évaluation clinique de la neuropathie diabétique. La neuropathie diabétique est une maladie complexe impliquant une perte progressive de fibres nerveuses. Le dépistage initial et le diagnostic en pratique clinique dépendent généralement de l'investigation de symptômes rapportés par le patient. Nous avons besoin d'outils objectifs, simples et dont les résultats sont reproductibles pour évaluer facilement ces patients en pratique clinique. A l'Université du Michigan, nous avons développé un programme de surveillance de la neuropathie en externe. Les patients remplissent un questionnaire et subissent un examen de dépistage rapide, le test de dépistage de la neuropathie. Chez les patients dont l'épreuve de dépistage est positive, la neuropathie diabétique est confirmée et classifiée selon le stade clinique au moyen d'un examen neurologique quantitatif et d'études de la conduction nerveuse, l'échelle de la neuropathie diabétique. Ce programme a été comparé à des instruments d'évaluation bien établis et il s'est avéré sensible et reproductible pour le dépistage et le diagnostic de la neuropathie diabétique. Nous croyons que ce programme fournit un outil précieux pour le clinicien en pratique courante et devrait permettre un diagnostic et une intervention précoces dans cette affection.
\end{abstract}

Can. J. Neurol. Sci. 1994; 21: Suppl. 4-S3-S7

The peripheral nervous system complications of diabetes are familiar and include symmetric diffuse, distal symmetric polyneuropathy, primarily sensorimotor, or painful sensory neuropathy, and autonomic neuropathy. The asymmetric or focal and multifocal nervous system complications of diabetes are not discussed here, but include radiculopathy or polyradiculopathy, amyotrophy, multiple mononeuropathies or mononeuropathy multiplex. The most common nervous system complication, distal symmetric polyneuropathy, is characterized by progressive nerve fiber loss. In some patients, such nerve fiber loss is accompanied by distal lower extremity pain and paresthesias while, in others, the feet become insensitive. Initial screening and diagnosis of diabetic neuropathy in the clinical setting relies upon both the subjective assessment of symptoms and an objective assessment of signs. This discussion provides a historical perspective of methods used to assess neuropathy, describes a neuropathy program developed at the University of Michigan, and highlights some results from the recently completed Diabetes Control and Complications Trial.'

\section{Peripheral Nerve System}

One form of peripheral nervous system injury is axonal degeneration, characterized by a slowly progressive distal axonal loss with secondary myelin loss. These constellation of findings is commonly seen in diabetic neuropathy. When sural nerve biopsies from normal, healthy patients are compared to those

From the Neuromuscular Section. Department of Neurology, (E.L.F.) and the Department of Endocrinology, (M.J.S.) University of Michigan, Ann Arbor. Reprint requests to: Eva L. Feldman, MD. PhD, Department of Neurology, University of Michigan Medical Center, 200 Zina Pitcher Place, Room 4414 Kresge III, Ann Arbor. MI, USA 48109-0588 
from age-matched diabetic patients, the remarkable finding in the diabetic nerve is axonal loss with a concomitant decrease in fiber density. Axon loss and decreased fiber density herald the onset of neuropathy. Neuropathy worsens as fiber loss progresses, and severe fiber loss predisposes to foot ulceration.

The typical symptoms of polyneuropathy are distal and symmetric and involve the lower more than the upper limbs. Patients usually complain of numbness, paresthesias, and a tingling or prickling feeling. Pain, burning and aching, particularly at night, are common patient complaints. In more severe cases, patients complain of distal weakness. Neurologists most commonly see diabetic patients who are referred because of neuropathic symptoms. In contrast, primary care physicians, diabetologists, and endocrinologists frequently see patients who are asymptomatic, even though they display severe sensory loss when quantitated by clinical examination and/or electrophysiological tests.

Typical signs in patients with polyneuropathy include symmetric distal sensory loss, which affects the lower more than the upper limbs. Loss of large myelinated fibers results in abnormal vibratory sense while abnormal pain and light touch sensation are secondary to the loss of small myelinated fibers. Reflexes are hypoactive, particularly the Achilles tendon reflex, and weakness when present is usually mild and distal.

\section{Assessment: Historical Perspective}

From a historical perspective, the prevalence of neuropathy has been determined by either subjective complaints, signs or nerve conduction studies (Table 1). ${ }^{2.3}$ In Rochester, Minnesota, where much of the recent epidemiologic work on diabetic neuropathy has been done, the prevalence of neuropathy among diabetic patients was $40 \%$ based on nerve conduction studies and quantitative examination. ${ }^{4}$

In the late 1970s, three assessment instruments were developed at the Mayo Clinic to quantify clinical neuropathy: the Neuropathy Symptom Profile, the Neuropathy Symptom Score, and the Neuropathy Disability Score. The Neuropathy Symptom Profile is a standardized questionnaire taken by the patient, consisting of more than 200 questions. ${ }^{5}$ It consists of four main profiles: neuropathy, weakness, sensory, and autonomic. The profile is considered abnormal if the patient scores above the 99 th percentile. The Neurology Symptom Score, a much briefer symptom assessment, adminstered by the physician to the patient, assesses the presence of sensory and autonomic neuropathy symptoms. The Neuropathy Disability Score is a quantitative, neurologic examination, is comparable to a complete neurological exam, and includes assessments of cranial nerves, muscle strength, and reflexes. ${ }^{6}$ Sensation is evaluated by touch, pinprick, vibration, and joint position sense and is performed on both of the index fingers and the dorsum of both great toes.

Dyck and colleagues administered these three instruments to 36 diabetic patients, who then underwent sural nerve biopsies. ${ }^{7}$ Histomorphometric changes in sural nerve biopsies correlated with abnormalities in sural nerve sensory amplitude and peroneal motor amplitude. This finding has been confirmed in other studies. ${ }^{8}$ Additionally, Dyck and coworkers found that an abnormal Neuropathy Disability Score correlated with fiber loss, change in fiber diameter, and abnormal electrophysiology. These findings indicate that diabetic neuropathy can be evaluated by a quantitative clinical exam and nerve conduction studies.
Table 1. Prevalence of diabetic neuropathy

\begin{tabular}{llcc}
\hline Country (year) & Assessment Method & $\begin{array}{c}\text { No. of } \\
\text { Patients }\end{array}$ & $\begin{array}{c}\text { Prevalence } \\
(\%)\end{array}$ \\
\hline U.S. (1953) & Subjective complaints & 261 & 62 \\
England (1953) & General findings & 100 & 57 \\
Belgium (1965) & Objective findings & 1,175 & 21 \\
Sweden (1950) & Objective findings & 150 & 49 \\
U.S. (1961) & Nerve conductions & 103 & 42 \\
U.S. (1958) & Impotence & 198 & 55 \\
Canada (1961) & Objective signs & 100 & 52 \\
U.S. (1951) & General signs & 77 & 35 \\
U.S. (1966) & Objective signs, nerve conductions & 107 & 10 \\
Denmark (1968) & Nerve conductions & 14 & 100 \\
England (1971) & Nerve conductions & 39 & 100 \\
Scotland (1977) & Nerve conductions & 10 & 100 \\
\hline
\end{tabular}

(From Schoenberg and Melton, $1993^{2}$, with permission)

In 1988, the San Antonio consensus group met to discuss the assessment of neuropathy and concluded that diagnosis of neuropathy should include a quantitative assessment of (1) symptoms, (2) neurologic examination, (3) sensory loss, (4) autonomic function, and (5) electrophysiology. ${ }^{9}$ A staging system for neuropathy was subsequently developed using the Neuropathy Symptom Score, Neuropathy Disability Score, the nerve conduction studies, quantitative sensory testing, autonomic function, and the Neuropathy Symptom Profile. ${ }^{4}$ The reproducibility of this staging system was evaluated in 20 patients. ${ }^{10}$ The complete panel of assessments was administered independently by three neurologists to each patient and repeated three to five days later. A high degree of reproducibility was found for nerve conduction studies, quantitative sensory testing, and for the Neuropathy Disability Score. ${ }^{10}$

\section{Michigan Neuropathy Rating Scale}

The recommendations for neuropathy assessment from the San Antonio conference ${ }^{9}$ and from Dyck, ${ }^{3}$ although valuable for use in clinical trials, have more limited applicability in clinical practice because of time and manpower requirements. Consequently, a new two-step program was developed at the University of Michigan." The first part, the Neuropathy Screening Instrument, consists of a 15-item questionnaire on foot sensation, including numbness, burning, and sensitivity (Table 2), and a brief clinical examination, which includes foot inspection, assessment of vibration sensation at the dorsum of the great toe, and grading of ankle reflexes (Table 3). A patient who has a positive score on the clinical exam $(>2)$ is referred to a neurologist for completion of the second part of the program. The second part, the Diabetic Neuropathy Score, consists of a clinical neurological examination and nerve conduction studies (Table 4). Sensation, including vibration, pin prick, and light touch; distal muscle strength; and reflexes (biceps, triceps, quadriceps femoris and Achilles) are assessed. An electrodiagnostic examination is performed examining sural, median and ulnar sensory nerves and peroneal and median motor nerves. The quantitative examination score is coupled with the number of abnormal nerve conductions to determine a composite Diabetic Neuropathy Score. ${ }^{11}$ 
Table 2. Neuropathy Screening Instrument Questionnaire

Please take a few minutes to answer the questions below about the feeling in your legs and feet.

Check yes or no based on how you usually feel.

1. Are your legs or feet numb?

2. Do you ever have any burning pain in your legs or feet?

3. Are your feet too sensitive to touch?

4. Do you get muscle cramps in your legs or feet?

5. Do you ever have any prickling feelings in your legs or feet?

6. Does it hurt when the bed covers touch your skin?

7. When you get into the tub or shower, are you able to tell the hot water from the cold water?

8. Have you ever had an open sore on your foot?

9. Has your doctor ever told you that you have diabetic neuropathy?

10. Do you feel weak all over most of the time?

11. Are your symptoms worse at night?

12. Do your legs hurt when you walk?

13. Are you able to sense your feet when you walk?

14. Is the skin on your feet so dry that it cracks open?

15. Have you ever had an amputation?

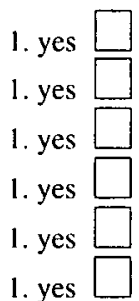

2. no

2. no

2. no

2. no

2. no

2. no

1. yes $\square$

1. yes $L$

2. no

2. no

1. yes $\square$

1. yes

1. yes

1. yes

1. yes

1. yes

1. yes

TOTAL:

(From Feldman et al., 1994'l, with permission)

Table 3. Neuropathy Screening Instrument

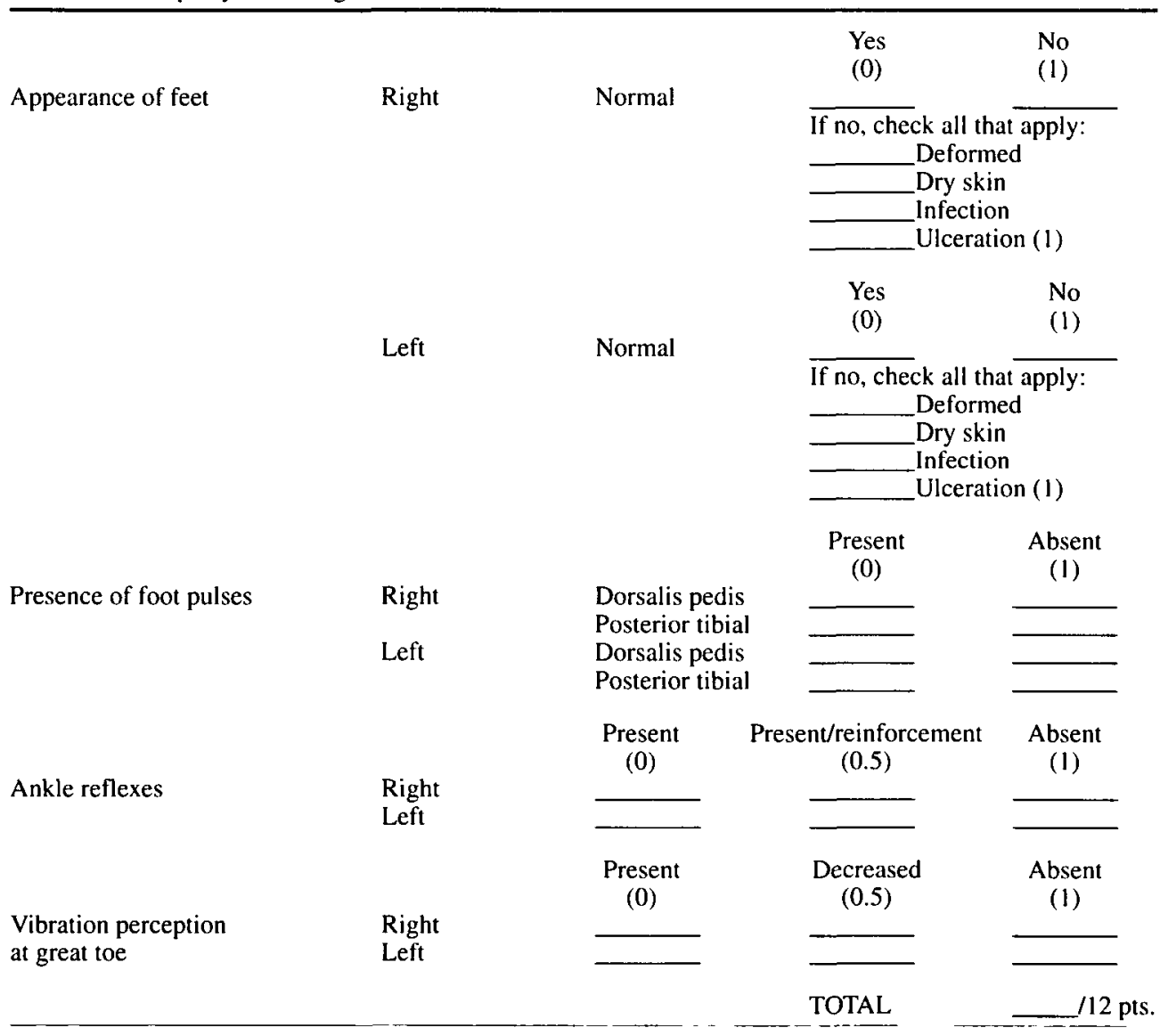




\begin{tabular}{|c|c|c|c|}
\hline \multicolumn{4}{|l|}{ Sensory Impairment } \\
\hline $\begin{array}{l}\text { Right } \\
\text { Vibration at big toe } \\
10 \text { gr filament } \\
\text { Pin prick on dorsum of } \\
\text { great toe }\end{array}$ & $\begin{array}{c}\text { Normal } \\
0 \\
0 \\
\text { Painful } \\
0\end{array}$ & $\begin{array}{c}\text { Decreased } \\
1 \\
1 \\
\frac{\text { Not Painful }}{2}\end{array}$ & $\begin{array}{c}\text { Absent } \\
2 \\
2\end{array}$ \\
\hline $\begin{array}{l}\frac{\text { Left }}{\text { Vibration at big toe }} \\
10 \mathrm{gr} \text { filament } \\
\text { Pin prick on dorsum of } \\
\text { great toe }\end{array}$ & $\begin{array}{c}\text { Normal } \\
0 \\
0 \\
\text { Painful } \\
0\end{array}$ & $\begin{array}{c}\text { Decreased } \\
1 \\
1 \\
\text { Not Painful } \\
2\end{array}$ & $\begin{array}{c}\text { Absent } \\
2 \\
2\end{array}$ \\
\hline \multicolumn{4}{|l|}{ Muscle Strength Testing } \\
\hline $\begin{array}{l}\text { Right } \\
\text { Finger spread } \\
\text { Great toe extension } \\
\text { Ankle dorsiflexion }\end{array}$ & $\begin{array}{c}\text { Normal } \\
0 \\
0 \\
0\end{array}$ & $\begin{array}{c}\text { Mild to Moderate } \\
1 \\
1 \\
1\end{array}$ & $\begin{array}{c}\text { Absent } \\
3 \\
3 \\
3\end{array}$ \\
\hline $\begin{array}{l}\text { Left } \\
\text { Finger spread } \\
\text { Great toe extension } \\
\text { Ankle dorsiflexion }\end{array}$ & $\begin{array}{c}\text { Normal } \\
0 \\
0 \\
0\end{array}$ & $\begin{array}{c}\text { Mild to Moderate } \\
1 \\
1 \\
1\end{array}$ & $\begin{array}{c}\text { Absent } \\
3 \\
3 \\
3\end{array}$ \\
\hline \multicolumn{4}{|l|}{ Reflexes } \\
\hline $\begin{array}{l}\text { Right } \\
\text { Biceps brachii } \\
\text { Triceps brachii } \\
\text { Quadriceps femoris } \\
\text { Achilles }\end{array}$ & $\begin{array}{l}\text { Present } \\
0 \\
0 \\
0 \\
0\end{array}$ & $\begin{array}{c}\text { Present with Reinforcement } \\
1 \\
1 \\
1 \\
1\end{array}$ & $\begin{array}{c}\text { Absent } \\
2 \\
2 \\
2 \\
2\end{array}$ \\
\hline $\begin{array}{l}\underline{\text { Left }} \\
\text { Biceps brachii } \\
\text { Triceps brachii } \\
\text { Quadriceps femoris } \\
\text { Achilles }\end{array}$ & $\begin{array}{c}\text { Present } \\
0 \\
0 \\
0 \\
0\end{array}$ & $\begin{array}{c}\text { Present with Reinforcement } \\
1 \\
1 \\
1 \\
1\end{array}$ & $\begin{array}{c}\text { Absent } \\
2 \\
2 \\
2 \\
2\end{array}$ \\
\hline
\end{tabular}

A comparison was made between the Michigan Program and the protocol designed by Dyck and colleagues in 56 patients from the diabetes clinic at the University of Michigan. When results from the different instruments were compared, the Neuropathy Screening Instrument correlated with the Neuropathy Disability Score, abnormal vibration threshold and abnormal autonomic function and nerve conduction testing. Similarly, the Diabetic Neuropathy Score correlated with the Neuropathy Disability Score and with nerve conductions, quantitative sensory, and autonomic function studies. Thus, the Neuropathy Screening Instrument and the Diabetic Neuropathy Score provide a good instrument for screening and diagnosis of diabetic neuropathy." A classification was developed based on the two-part Michigan program, with stages that range from no neuropathy to severe neuropathy (Table 5). The entire examination takes about 45 minutes to administer.

\section{Clinical Evaluation}

The rationale behind the effort to quantitate diabetic neuropathy is emphasized by the results from the Diabetic Control and Complications Trial, which were recently reported.' The goal of the trial was to determine whether intensive insulin treatment affected the incidence of long-term diabetic complications. This full-scale trial was initiated in 1985; it terminated in 1993. The trial enrolled 1,441 diabetic patients, who were placed into either a primary prevention or a secondary intervention group.

Patients placed on conventional treatment administered insulin twice daily and self-monitored blood glucose levels. Hemoglobin $\mathrm{A}_{\mathrm{IC}}\left(\mathrm{HbA}_{\mathrm{IC}}\right)$ was measured quarterly, and patients were encouraged to adjust treatment if the level was greater than $13.1 \%$. The goal was to have no symptoms of hyperglycemia or hypoglycemia. The intensive therapy group had the same clinical goals as the conventional therapy group but also attempted to maintain blood glucose as close to normal as possible, (i.e., a fasting blood glucose of 70 to $120 \mathrm{mg} / \mathrm{dL}$, postprandial levels $<180 \mathrm{mg} / \mathrm{dL}, 3 \mathrm{AM}$ levels of $>5 \mathrm{mg} / \mathrm{dL}$, and an $\mathrm{HbA}_{\mathrm{IC}} \leq 6.05 \%$ ). Patients received at least four daily insulin injections or were placed on an insulin pump, and at least four daily blood tests were obtained. In the conventional therapy group, the median $\mathrm{HbA}_{\mathrm{IC}}$ was $8.9 \%$, and only $1.2 \%$ of more than $17,000 \mathrm{HbA}_{\mathrm{IC}}$ readings were greater than $13.1 \%$. In the intensive therapy group, the median $\mathrm{HbA}_{1 \mathrm{C}}$ was $7.2 \%$, and $44 \%$ of the patients achieved an $\mathrm{HbA}_{1 \mathrm{C}}$ of less than $6 \%$. The difference in $\mathrm{HbA}_{\mathrm{IC}}$ between the two groups was $1.5 \%$ to $2 \%$ throughout the study.

Patients were evaluated for neuropathy by way of a history, a neurologic examination, and neurophysiological and autonomic testing. A neurologist administered a symptom questionnaire and performed a neurologic examination. Symptoms of neuropathy, an abnormal sensory exam consistent with neuropathy, 
Table 5. Diabetic neuropathy staging based on the neuropathy scoring system developed at the University of Michigan.

\begin{tabular}{lcc} 
Stage & $\begin{array}{c}\text { No. of Nerve Conduction } \\
\text { Abnormalities }\end{array}$ & $\begin{array}{c}\text { Neuropathy Screening } \\
\text { Instrument Score }\end{array}$ \\
\hline $0=$ none & $\leq 1$ & $\leq 6$ \\
$1=$ mild & 2 & $<12$ \\
$2=$ moderate & $3-4$ & $<29$ \\
$3=$ severe & $\geq 5$ & $<46$ \\
\hline
\end{tabular}

and deep tendon reflexes were graded as present or absent. If two of these three parameters were present and if the patient had two abnormal nerve conduction studies, then the patient was considered to have definite clinical neuropathy. Patients were evaluated at baseline, at five years and study termination.

The risk reduction rate for developing diabetic neuropathy was $70 \%$ in the primary prevention group and $58 \%$ in the secondary intervention group for intensive therapy compared with conventional therapy. Combining the cohorts, the risk reduction for neuropathy was $61 \%$ with intensive insulin therapy. The five-year prevalence of new outcomes was reduced by $55 \%$, $50 \%$, and $43 \%$ for clinical, nerve conduction, and autonomic testing, respectively, with intensive insulin therapy compared with conventional therapy.

\section{SUMMARY}

Early diagnosis of diabetic neuropathy is important in the prevention of long term foot complications. Even though there are a number of invasive and noninvasive methods available that are appropriate for assessing neuropathy in clinical trials, the clinician has only a limited number of tools available that are practical, reliable, and reproducible for screening, diagnosing and monitoring neuropathy in the practice setting. The Michigan neuropathy program offers one approach to the clinical assessment and monitoring of neuropathy and was developed to meet the needs of the clinician.

\section{REFERENCES}

1. Diabetes Control and Complications Trial Research Group. The effect of intensive treatment of diabetes on the development and progression of long-term complications in insulin-dependent diabetes mellitus. N Engl J Med 1993; 329: 977-986.

2. Schoenberg BS, Melton LJ. Epidemiologic approaches to peripheral neuropathy $I n$ : Dyck PJ, Thomas PK, eds. Peripheral Neuropathy. Philadelphia, PA: W.B. Saunders Company; 1993: 775-782.

3. Pirart J. Diabetes mellitus and its degenerative complications: a prospective study of 4,400 patients between 1947 and 1973 . Diabetes Care 1978; 1: 168-188, 252-263.

4. Dyck PJ. Detection, characterization, and staging of polyneuropathy: assessed in diabetics. Muscle Nerve 1988; 11: 21-32.

5. Dyck PJ, Karnes JL, O'Brien PC, Swanson CJ. Neuropathy symptom profile in health, motor neuron disease, diabetic neuropathy and amyloidosis. Neurology 1986; 36: 1305-1308.

6. Dyck PJ, Sherman WR, Hallcher LM, et al. Human diabetic endoneurial sorbitol, fructose and myo-inositol related to sural nerve morphometry. Ann Neurol 1980; 8: 590-596.

7. Dyck PJ, Karnes JL, Daube JR, O'Brien PC, Service FJ. Clinical and neuropathological criteria for the diagnosis and staging of diabetic polyneuropathy. Brain 1985; 108: 861-880.

8. Sima AAF, Bril V, Nathaniel V, et al. Regeneration and repair of myelinated fibers in sural-nerve biopsy specimens from patients with diabetic neuropathy treated with sorbinil. N Engl J Med 1988; 319: 548-555.

9. Consensus Statement of the American Diabetes Association and the American Academy of Neurology: Report and Recommendations of the San Antonio Conference on Diabetic Neuropathy. Diabetes 1988; 37: 1000-1004.

10. Dyck PJ, Kratz KM, Lehman KA, et al. The Rochester Diabetic Neuropathy Study: design, criteria for types of neuropathy, selection bias, and reproducibility of neuropathic tests. Neurology 1991; 41: 799-807.

11. Feldman EL, Stevens MJ, Thomas PK, et al. A practical two-step quantitative clinical and electrophysiological assessment for the diagnosis and staging of diabetic neuropathy. Diabetes Care 1994 ; in press. 